\title{
ВЛИЯНИЕ ФАКТОРОВ ВНЕШНЕЙ СРЕДЫ НА ДИНАМИКУ РАЗВИТИЯ КРЕДИТНОГО РЫНКА В РАЗРЕЗЕ КЛЮЧЕВЫХ ГРУПП КРЕДИТНЫХ ПРОДУКТОВ
}

\author{
(c) 2019 Конников Евгений Александрович \\ Санкт-Петербургский политехнический университет Петра Великого (СПбПУ), \\ Институт промышленного менеджмента, экономики и торговли, \\ Высшая инженерно-экономическая школа, Россия, Санкт-Петербург \\ Санкт-Петербургский государственный экономический университет (СПБГЭУ), \\ Кафедра банков, финансовых рынков и страхования, Россия, Санкт-Петербург \\ Email: konnikov.evgeniy@gmail.com

\section{(C) 2019 Панкова Людмила Владимировна} \\ кандидат экономических наук, доцент \\ Санкт-Петербургский политехнический университет Петра Великого (СПбПУ), \\ Институт промышленного менеджмента, экономики и торговли, \\ Высшая инженерно-экономическая школа, Россия, Санкт-Петербург \\ Email: pankova_lv@spbstu.ru

\section{(c) 2019 Федорова Екатерина Эдуардовна} \\ Санкт-Петербургский политехнический университет Петра Великого (СПбПУ), \\ Институт промышленного менеджмента, экономики и торговли, \\ Высшая инженерно-экономическая школа, Россия, Санкт-Петербург \\ Email: kate_fedorova@icloud.com
}

В условиях эволюции систем потребления, роста численности населения, ценностной трансформации, динамики курса национальной валюты и падения реальных доходов населения возрастает потребность домохозяйств в заёмных средствах, что определяет актуальность текущего исследования. Описанные тенденции находят свое отражение в многогранной совокупности факторов внешней среды, которые могут быть определены количественно. Следовательно, математическая формализация влияния соответствующих факторов позволит определить вектор и специфику развития кредитного рынка. Цель данного исследования - определение и формализация специфики влияния различных факторов внешней среды на развитие ключевых сегментов отечественного рынка кредитования, а именно: рынок ипотечного кредитования, рынок кредитования малого и среднего предпринимательства и рынок автокредитования. По результатам исследования была получена система эконометрических уравнений, описывающих динамику развития соответствующих сегментов. Ключевым выводом является утверждение о том, что комплекс экономических факторов внешней среды оказывает сравнительно большее влияние на принятие заёмщиками решения об обращении в кредитные организации, чем комплекс социальных факторов.

Ключевые слова: кредитный рынок, рынок ипотечного кредитования, рынок кредитов субъектам малого и среднего предпринимательства, рынок автокредитования, кредитный продукт.

Расширение ассортимента новейших товаров и услуг, рост численности населения и изменения экономической ситуации в России приводят к росту потребности населения и бизнеса в заёмных средствах [5]. Вследствие этого вопрос развития рынков кредитования является актуальным. Целью данного исследования является определение и формализация специфики влияния различных факторов внешней среды на развитие ключевых сегментов отечественного рынка кредитования. Объектом данного иссле- дования выступает рынок кредитования физических и юридических лиц Российской Федерации, в разрезе его ключевых сегментов (рынка ипотечного кредитования, рынка кредитования малого и среднего предпринимательства и рынка автокредитования). Предметом исследования выступает зависимость объёмов выдаваемых кредитов от факторов внешней среды.

Вопрос развития рынка кредитования активно рассматривается в отечественной и зарубежной научной литературе. В статье «Ежемесячные 
тенденции экономического развития России» [6] на основе данных Федеральной службы государственной статистики РФ [12] исследуются факторы внешней среды, оказывающие влияние на рост цены нефти и падение курса национальной валюты, а также описывается текущая ситуация на рынке труда. Авторы резюмируют статью следующим образом: «Благодаря высоким ценам на нефть, улучшению налогового администрирования, ослаблению рубля и консервативной налогово-бюджетной политике, в 2018 году бюджет сводится с профицитом». Подобный вывод указывает на возможную неоднозначную динамику развития рынков кредитования, что может привести к повышению дисперсии результирующих показателей деятельности банков. По оценкам рейтингового агентства «Эксперт» (RAEX) [14], в 2018 году лицензии могут потерять более 60 банков, а потенциал повышения прибыли банков от кредитования будет существенно ограничен незначительным ростом экономики и нехваткой капитала, направляемого на покрытие растущих кредитных рисков. Избыточная ликвидность, образовавшаяся из-за нехватки финансово устойчивых заемщиков, усиливает давление на рентабельность банковского бизнеса. В обзоре отдельно отмечается - «Падение маржинальности кредитования банки будут пытаться компенсировать за счет наращивания непроцентных доходов». При этом драйвером рынка кредитования останутся розничные ссуды. Основываясь на данной динамике развития рынков кредитования, в статье [3] Бровкиной
Натальей Евгеньевной был предложен подход к регулированию деятельности банковской системы, опирающийся на пропорции развития кредитного рынка. На основании эмпирического исследования был сделан вывод о том, что для достижения стабильности необходимо регулирование кредитного рынка в соответствии с выявленными пропорциями его развития [4]. По мнению Бровкиной Н.Е., необходимо переосмыслить роль кредита в экономике, изменить управленческие подходы с целью трансформации регулирования кредитного рынка в направлении соблюдения предложенных пропорций. Подобные выводы относительно необходимости трансформации подходов к регулированию рынков кредитования, нашли свое отражение во многих исследованиях $[1,2,5,7,8]$. Однако авторы рассматривают либо только одну из кредитных ниш, либо общую ситуацию на кредитном рынке в Российской Федерации. При этом, целесообразно дифференцировать рынок кредитования в соответствии с ключевыми кредитными продуктами и определить факторы, оказывающие на них влияние или исключить зависимость факторов-результатов от признак-факторов.

Для целей проведения данного исследования были выбраны показатели, дифференцированные во времени, отражающие совокупность информации, которая потенциально может определять состояние рынка кредитования Российской Федерации. Совокупность данной информации представлена в таблице 1.

Решение задач эконометрики осуществляет-

Таблица 1. Исследуемый массив статистической информации

\begin{tabular}{|c|l|c|c|c|c|}
\hline No & \multicolumn{1}{|c|}{ Переменная } & Характер & $\begin{array}{c}\text { Условное } \\
\text { обозначение }\end{array}$ & $\begin{array}{c}\text { Единица } \\
\text { изерения }\end{array}$ & Ссылка \\
\hline 1. & $\begin{array}{l}\text { Ипотечные жилищные кредиты, } \\
\text { предоставленные физическим лицам }\end{array}$ & Эндогенный & $\mathrm{Y}_{1}$ & Млн.руб. & {$[9,12]$} \\
\hline 2. & $\begin{array}{l}\text { Объем кредитов, предоставленных } \\
\text { субъектам малого и среднего пред- } \\
\text { принимательства }\end{array}$ & Эндогенный & $\mathrm{Y}_{2}$ & Млн.руб. & {$[8,12]$} \\
\hline 3. & Автокредиты & Эндогенный & $\mathrm{Y}_{3}$ & Тыс. ед. & {$[10,7]$} \\
\hline 4. & Уровень безработицы & Экзогенный & $\mathrm{X}_{1}$ & \% & {$[12]$} \\
\hline 5. & Уровень инфляции & Экзогенный & $\mathrm{X}_{2}$ & \% & {$[11]$} \\
\hline 6. & Прожиточный минимум & Экзогенный & $\mathrm{X}_{3}$ & Руб. & {$[11]$} \\
\hline 7. & Количество родившихся & Экзогенный & $\mathrm{X}_{4}$ & Чел. & {$[11]$} \\
\hline 8. & Коэффициент жизнеспособности & Экзогенный & $\mathrm{X}_{5}$ & \% & {$[11]$} \\
\hline 9. & Количество браков & Экзогенный & $\mathrm{X}_{6}$ & Штук & {$[11]$} \\
\hline 10. & Численность выбывших работников & Экзогенный & $\mathrm{X}_{7}$ & Тыс. чел. & {$[12]$} \\
\hline 11. & $\begin{array}{l}\text { Среднемесячная номинальная начис- } \\
\text { ленная заработная плата работников }\end{array}$ & Экзогенный & $\mathrm{X}_{8}$ & Руб. & {$[12]$} \\
\hline 12. & $\begin{array}{l}\text { Средневзвешенная\% ставка по } \\
\text { выданным с начала года кредитам }\end{array}$ & Экзогенный & $\mathrm{X}_{9}$ & \% & {$[12]$} \\
\hline
\end{tabular}


ся с использованием математических моделей, построенных на основе эмпирических данных. В данном случае разрабатываются множественные регрессионные модели, не содержащие авторегрессионной компоненты или компоненты скользящего среднего. Выбранный класс моделей позволит максимально точно определить степень влияния параметров X на результирующие показатели Y. Алгоритм построения данных моделей подразумевает использования в качестве ключевого аналитического показателя p-значение. Путём одной или нескольких итераций исключения факторы на основе р-значения, формируются оптимальные регрессионные модели.

На основе данных в таблице 1 по каждой модели были составлены три уравнения и проанализированы аналитические показатели. Повторное построение множественных регрессий позволило получить результаты, на основе которых в дальнейшем были составлены выводы. В соответствии с проведённым анализом мы получили следующее уравнение для рынка ипотечного кредитования:

$Y_{1}=24276005,75-1654394 \times X_{9}+1035,03 \times X_{3}$ $+0,12 \times X_{4}-4,1 \times X_{6}$

Коэффициент детерминации данного уравнения составляет 0,79. Это означает, что 79\% вариации объясняемой переменной $\mathrm{Y}_{1}$ объясняется вариацией экзогенных переменных, включенных в модель. Высокие значения Р-значений определили необходимость исключения комплекса социальных признак-факторов, таких как количество родившихся и количество браков. Финальная модель множественной регрессии для рынка ипотечного кредитования примет следующий вид:

$$
Y_{1}=15699659-1481350,39 \times X_{9}+1256,93 \times X_{3}
$$

Коэффициент детерминации данной модели составляет 0,79. Данный результат незначительно отличается от результата прошлой итерации. Р-значения экзогенных факторов принимает допустимые значения. Среднее отклонение расчетных значений от фактических составляет $14,4 \%$, что указывает на высокое качество модели.

Первичная модель множественной регрессии для рынка кредитования субъектам малого и среднего предпринимательства выглядит следующим образом:

$$
Y_{2}=-254127390-109001967 \times X_{2}+27898,44 \times
$$

$X_{7}+726,71 \times X_{8}$

Коэффициент детерминации данной модели составляет 0,702. По результатам расчётов Р-значений было решено не учитывать уровень инфляции. При этом, средняя ошибка аппроксимации составляет 0,006, то есть среднее отклонение расчетных значений от фактических практически отсутствует. Модель подобрана качественно, однако имеет смысл провести ещё одну итерацию для получения лучших результатов. Повторное построение модели множественной регрессии для данного рынка представлено в уравнении 4:

$$
Y_{2}=-183586433,9+20072,76 \times X_{7}+689,74 \times
$$
$X_{8}$

Коэффициент детерминации для данной модели составляет 0,567. Следовательно, 57\% вариации Y объясняется вариацией переменных $\mathrm{X}$. Следует сразу отметить, что значение показателя достаточно низкое для того, чтобы опираться на результаты регрессии и делать какие-либо выводы. Среднее отклонение расчетных значений от фактических составляет $12 \%$.

В завершении, приведем модель множественной регрессии для рынка автострахования:

$$
\begin{gathered}
Y_{3}=5358,39-0,03 \times X_{8}-1855,42 \times X_{5}+ \\
0,00028 \times X_{6}+0,00028 \times X_{6}-37020,42 \times X_{1}
\end{gathered}
$$

Всего 56\% вариации результирующей переменной Y объясняется вариацией факторов Х. При этом Р-значения слишком высокие, что вынуждает отказаться от включения в следующую итерацию такого фактора, как количество браков. Среднее отклонение расчетных значений от фактических составляет 1\%. Это свидетельствует о качественно подобранной модели. Вторая итерация модели представлена ниже:

$$
Y_{3}=6064,45-0,039 \times X_{8}-1883,77 \times X_{5}-
$$
$39822,27 \times X_{1}$

Коэффициент детерминации в данном случае составил 0,549. Величина показателя слишком низкая для того, чтобы опираться на результаты регрессии и делать какие-либо выводы. 
При этом среднее отклонение расчетных значений от фактических составляет всего 9,8\%.

Выводы относительно степени влияния факторов внешней среды на развитие рынков кредитования может быть выражено нормированными коэффициентами детерминации (рисунок $1)$.

Как можно видеть на графике, наиболее высокое значение нормированного коэффициента детерминации достигается для модели множественной регрессии для рынка ипотечных жилищных кредитов, предоставленных физическим лицам. В этом случае около $70 \%$ вариации результатов обусловлено величиной прожиточного минимума и средневзвешенной процентной ставкой по кредитам. В случае кредитов, предоставленных субъектам малого и среднего предпринимательства, коэффициент детерминации составляет $36,43 \%$, то есть доля влияния выбранных признак-факторов на изменение Y составляет лишь $1 / 3$. Худшее значение коэффициента достигается при исследовании рынка автокредитования.

По результатам анализа Р-значений установлено, что вероятности ошибки при отклонении нулевой гипотезы для рассмотренных признак-факторов достаточно низкие, самое большое значение наблюдается при анализе этого показателя для рынка автокредитования.

Стоит заметить, что среднее отклонение расчетных значений от фактических ниже всего именно в третьем случае. Данные для третьей модели подобраны лучше всего.

Таким образом, больше всего опираться можно на результаты построения множественной регрессии для ипотечного рынка. Выбранные факторы в данном случае способны объ- яснить гораздо большую часть вариации, чем в остальных двух случаях. То же самое можно сказать в случае увеличения массива данных, опираясь на значения нормированного коэффициента детерминации моделей.

Для Российской Федерации такие экономические факторы, как средневзвешенная процентная ставка по выданным с начала года кредитам и величина прожиточного минимума, оказывают большее влияние на оформление ипотечного кредита в сравнении с выбранными социальными факторами - количество браков по стране и количество родившихся детей.

Это означает, что даже при увеличении количества людей, проживающих в одной квартире/доме, не всегда принимается решение об улучшении жилищных условий. При этом увеличение прожиточного минимума и снижение процентной ставки по кредитам стимулируют население на изменение своего жилищного положения.

По мнению авторов, данный факт с негативной стороны характеризует способность домохозяйств Российской Федерации к повышению реального благосостояния. Отсутствие доступных заемных средств для населения может привести к ухудшению положения кредитных организаций, что в целом угрожает благосостоянию экономики страны.

Данное заключение подкреплено проведённым эконометрическим исследованием, и в рамках дальнейших исследований может быть дополнено расширенным массивом временного ряда и количества независимых переменных. Это поможет выявить новые закономерности, которые подтвердят или, наоборот, опровергнут выводы данной работы.

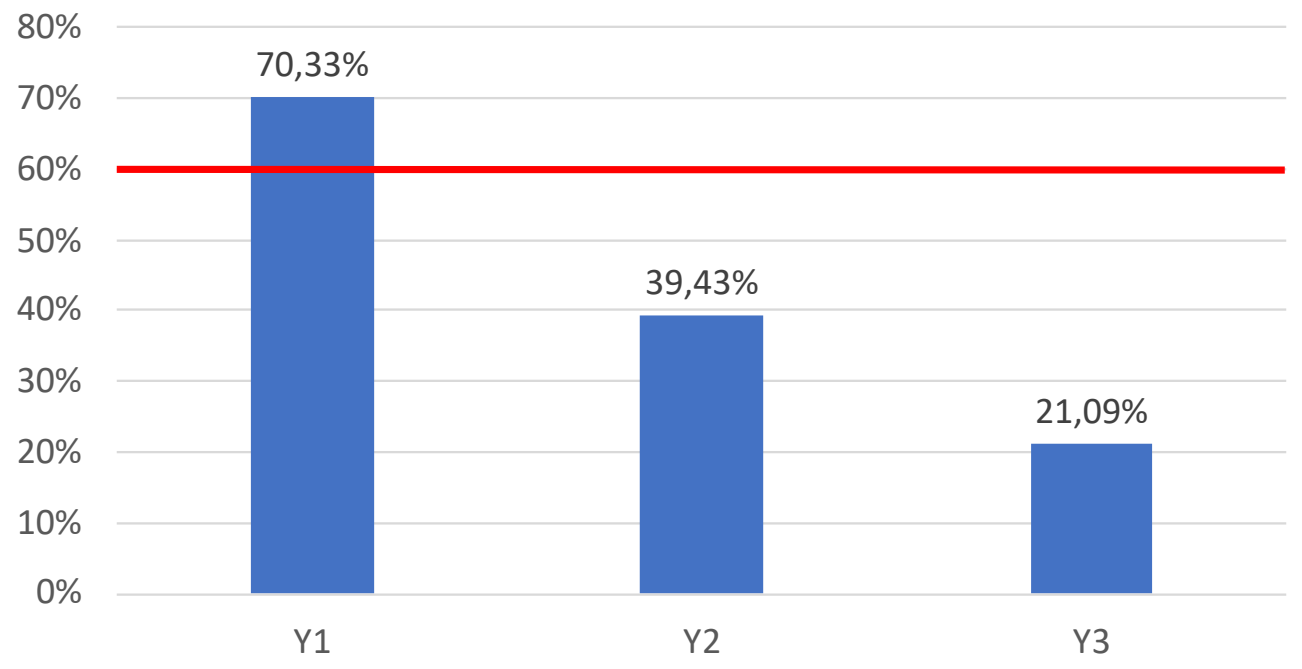

Puc. 1. Значения нормированных коэффициентов детерминации 


\section{Библиографический список}

1. Батаев А.В. Анализ тенденций в банковском секторе России и мире // В сборнике: ФИНАНСОВЫЕ РЕШЕНИЯ ХХІ ВЕКА: ТЕОРИЯ И ПРАКТИКА Сборник научных трудов 16-Й Международной научно-практической конференции. Санкт-Петербургский политехнический университет Петра Великого; Ответственные за выпуск Д.Г. Родионов, Т.Ю. Кудрявцева, Ю.Ю. Купоров. 2015. С. 327-336.

2. Батаев А.В. Анализ финансовых показателей и прогноз информатизации банковского сектора России в период кризиса // В сборнике: ФИНАНСОВЫЕ РЕШЕНИЯ ХХІ ВЕКА: ТЕОРИЯ И ПРАКТИКА СборнИК научных трудов 16-й Международной научно-практической конференции. Санкт-Петербургский политехнический университет Петра Великого; Ответственные за выпуск Д.Г. Родионов, Т.Ю. Кудрявцева, Ю.Ю. Купоров. 2015. С. 336-346.

3. Бровкина Н.Е. Пропорциональное развитие кредитного рынка как основа стабильности национальной банковской системы // Экономика. Налоги. Право. - 2018. - № 1. - С. 59.

4. Гусаков М.А., Родионов Д.Г., Николова Л.В. Секьюритизация банковских активов // В сборнике: Неделя науки СПбПУ сборник докладов научного форума с международным участием. Ответственные редакторы: Якубсон В.М., Кораблев В.В., Устинов С.М., Лиокумович Л.Б., Чернявская В.Е.. 2014. С. 164-170.)

5. Донецкова Ольга Юрьевна, Плужник Анна Борисовна, Садыкова Люция Мунировна Основные тенденции развития кредитования населения в России // АНИ: экономика и управление. 2017. № 4 (21). URL: https:// cyberleninka.ru/ article/n/osnovnye-tendentsii-razvitiya-kreditovaniya-naseleniya-v-rossii.

6. Ежемесячные тенденции экономического развития России. Сентябрь 2018 // Русипотека. URL: http:// rusipoteka.ru/files/analytics/worldbank/tendencii-ekonomicheskogo-razvitiya-rf-sent-2018.pdf.

7. Забелин Б.Ф., Забелин К.А., Конников Е.А. Доходность банка и бюджет клиента // Экономика и предпринимательство. 2017. № 8-1 (85). С. 526-528.

8. Мандрон В. В., Селемина К.С. Состояние и тенденции развития рынка ипотечного кредитования в России // Молодой ученый.-2017. - № 6. - C. 266-271.-URL https://moluch.ru/archive/140/ 37221/.

9. НБКИ и АВТОСТАТ: в 2016 году количество выданных в РФ автокредитов выросло на 14\% // Аналитическое агентство ABTOCTAT. URL: https://www.autostat.ru/press-releases/28813/

10. Объем рынка автокредитования России вырос более чем на 80\% с 2015 года // Информационное агентство RNS. URL: https://rns.online/finance/Obem-rinka-avtokreditovaniya-Rossii-viros-bolee-chem-na-80-s-2015goda-2017-10-03/

11. Официальный сайт Единой межведомственной информационно-статистической системы. URL: https:// www.fedstat.ru

12. Официальный сайт Федеральной службы государственной статистики. URL: http://www.gks.ru

13. Погребова O.A. К вопросу формирования стандартизированных решений о покупке на рынке велнес-товаров и услуг // В сборнике: Маркетинг и эффективность банковского бизнеса Материалы Международной научно-практической конференции. Под научной редакцией Н.А. Савинской. 2013. С. 252-260.

14. «Прогноз развития банковского сектора в 2018 году: кризис бизнес-модели // Рейтинговое агентство «Эксперт PA» - рейтинги, исследования, обзоры, конференции. URL: https://raexpert.ru/docbank/ 927/7be/854/ b6ebbffddbdd764d4765f39.pdf. 